\title{
De Winter sign in a patient with left main coronary artery occlusion
}

\author{
Murat Sunbul, Okan Erdogan, Osman Yesildag, Bulent Mutlu \\ Department of Cardiology, Faculty of Medicine, Marmara University, Istanbul, Turkey
}

Postep Kardiol Inter 2015; 11, 3 (41): 239-240

DOI: $10.5114 /$ pwki.2015.54019

\section{Case report}

A previously healthy 31-year-old man with a history of smoking presented with severe prolonged chest pain for more than one hour duration. ECG taken on admission revealed slightly widened QRS complexes, and ST segment elevations in leads $\mathrm{aVR}, \mathrm{aVL}, \mathrm{V}_{1}$ and $\mathrm{V}_{2}$ in contrast to up-sloping ST-segment depressions in leads $D_{\|}$, $\mathrm{D}_{\text {III, }}, \mathrm{VVF}$ and $\mathrm{V}_{3-6}$ at the J point (Figure $1 \mathrm{~A}$ ), which is called de Winter sign. Subsequent urgent coronary angiography revealed almost total occlusion of the left main coronary artery (LMCA) with severe thrombus formation (Figure 2) and poor distal filling of both the left anterior descending (LAD) and circumflex (CX). The patient underwent a successful coronary artery bypass grafting (CABG) operation with the bilateral internal mammary arteries to the LAD and CX. His post-op. ECG substantially improved, as shown in Figure 1 B. He was discharged 10 days later with optimal medical therapy.

Although the underlying mechanism remains elusive, de Winter sign is generally ascribed to occlusions in the proximal segment of the LAD artery and is not mentioned among the ECG patterns representing acute left main coronary artery (LMCA) occlusion [1, 2]. Unfortunately, there is no single type of ECG pattern indicating sudden total occlusion of the LMCA [3]. Various factors such as individual differences in coronary anatomy, recruitment of collateral channels and repeated episodes of ischemia with preconditioning, the size of the jeopardized myocardium, timing of the ECG recording, partial obstruction causing some residual flow and different phases of the thrombotic cascade may all be responsible for the differ-
A $\mathrm{mm} / \mathrm{mV} 25 \mathrm{~mm} / \mathrm{s}$ Average
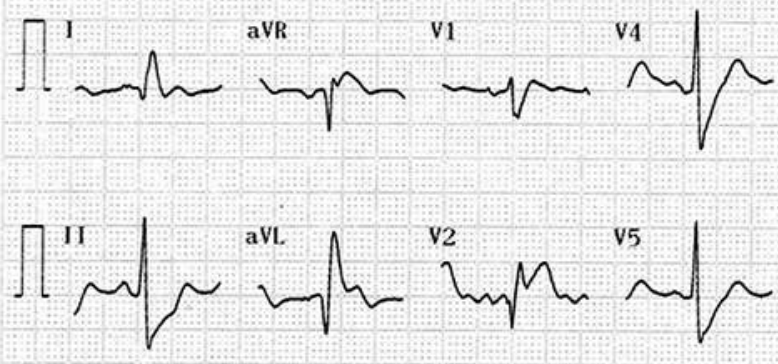

V5
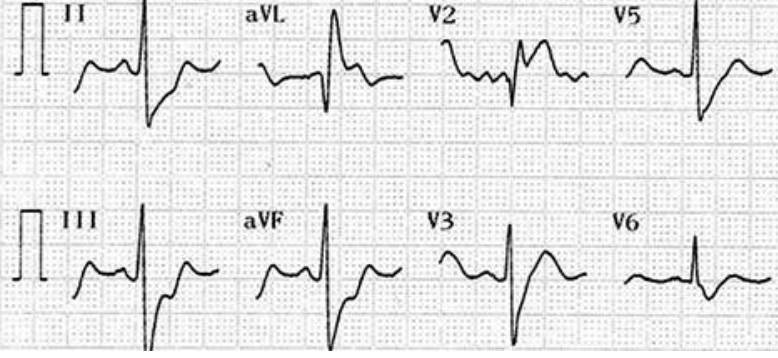

aVF
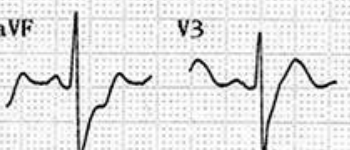

V6

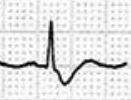

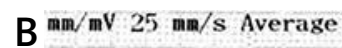
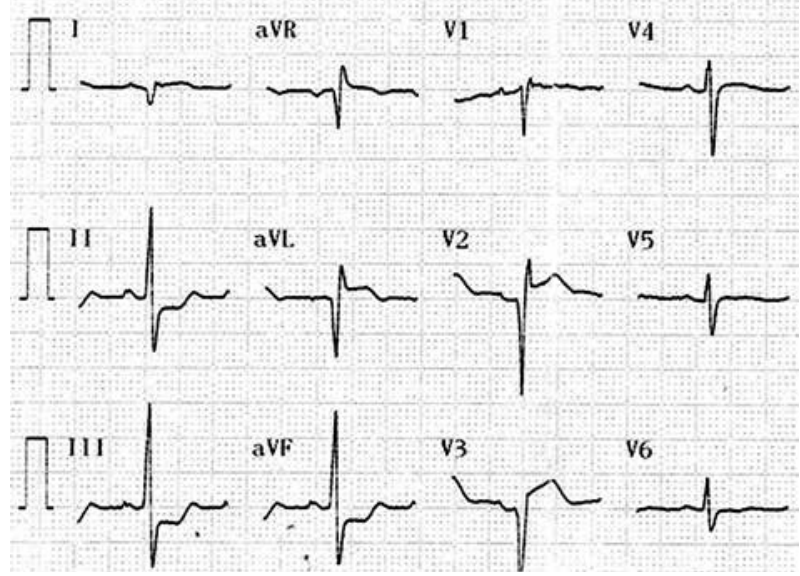

Figure 1. A - Surface ECG shows slightly widened QRS complexes, ST segment elevations in leads aVR, aVL, $V_{1}$ and $V_{2}$ in contrast to up-sloping ST-segment depressions in leads $D_{\| \prime}, D_{\| I}$, aVF and $V_{3-6}$ at the J point. $B$ - Post-op. ECG improved with some residual ST segment changes

\section{Corresponding author:}

Murat Sunbul MD, Department of Cardiology, Faculty of Medicine, Marmara University, Istanbul, Turkey, phone: +90 5065819015 , fax: +90 21665706 95, e-mail: drsunbul@yahoo.com.tr

Received: 2.04.2014, accepted: 14.05.2014. 


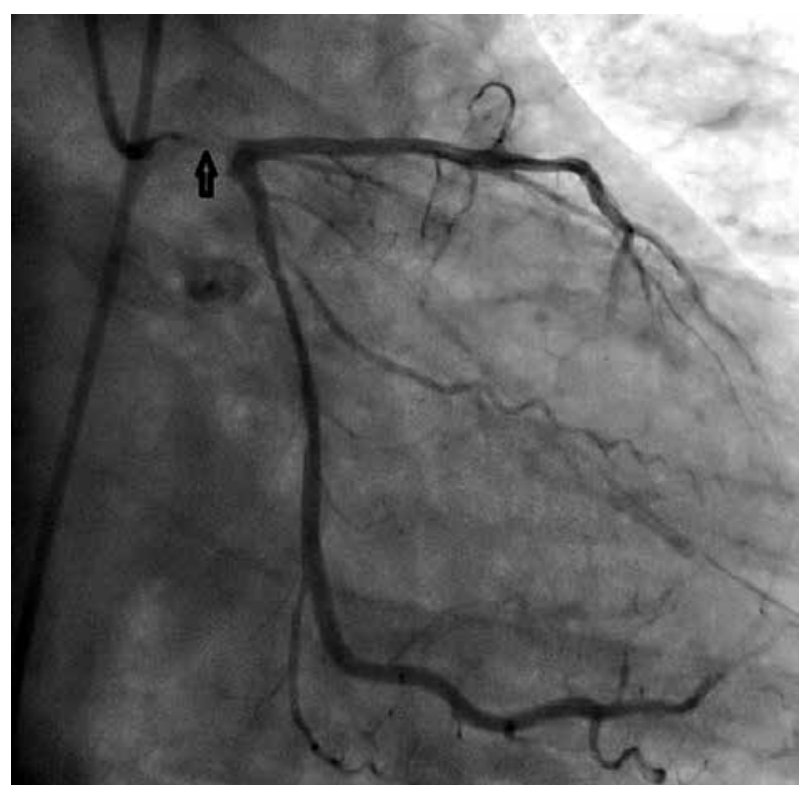

Figure 2. Coronary angiography shows total occlusion of the left main coronary artery with severe thrombus formation and poor distal filling of both left anterior descending and circumflex arteries

ent types of ECG changes. In conclusion, physicians and paramedics involved in the triage of patients with chest pain should be aware of de Winter sign because of its possible association with acute LMCA occlusion.

\section{Conflict of interest}

The authors declare no conflict of interest.

\section{References}

1. De Winter RJ, Verouden NJ, Wellens HJ, Wilde AA; Interventional Cardiology Group of the Academic Medical Center. A new ECG sign of proximal LAD occlusion. N Engl J Med 2008; 359: 2071-3.

2. Samadov F, Akaslan D, Cincin A, et al. Acute proximal left anterior descending artery occlusion with de Winter sign. Am J Emerg Med 2014; 32: 110.e1-3.

3. Yamaji H, Iwasaki K, Kusachi S, et al. Prediction of acute left main coronary artery obstruction by 12-lead electrocardiography. ST segment elevation in lead aVR with less ST segment elevation in lead V(1). J Am Coll Cardiol 2001; 38: 1348-54. 